DISCUSSION OF PAPER

\title{
'A STUDY OF THE INELASTIC SEISMIC RESPONSE OF REINFORCED CONCRETE COUPLED FRAME - SHEAR WALL STRUCTURES'
}

\author{
W.J. Goodsir, T. Paulay and A.J. Carr \\ (Vol 16, No. 3, September 1983, - )

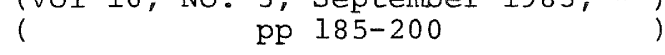

Discussion by - R.L. Williams:

(Ministry of Works and

Development, Hamilton)

I notice the system used strong colum-weak beam philosophy. As the presence of walls controls drift it appears that the necessity to avoid column hinging is not necessary. Have the authors considered allowing ductile column hinging in such a structure? I feel that the ductile column system would be more economical when long span beams are present.

Authors' reply:

The question is one of choice between column sway and beam sway mechanisms. In terms of overall behaviour, column hinging in buildings in which deformations due to earthquake effects are controlled by structureal walls, should not be objectionable. However, the authors would offer the following points for consideration.

(i) Due to axial compression it is a little more difficult to achieve significant ductility in columns than it is in beams.

(ii) Ductility demand in column hinges necessitates confining transverse reinforcement, the quantity of which is generally more than the additional transverse reinforcement required in potential hinges of beams.

(iii) When the elastic response of column is assured, up to $50 \%$ reduction of transverse reinforcement in the end region may be obtained.

(iv) Lapped splices must not be used in potential plastic hinge regions. However, they may be placed immediately above floor levels in columns with sufficient strength in excess of the adjoining beam or beams.

The authors agree that with long span beams it would be more economical to design for plastic hinges in columns rather than increase both column size and reinforcement content in order to produce flexural strength in excess of the strength of the beams.

Discussion by $\mathrm{S}$. Otani (University of Tokyo) :

Would the authors comment on the displacement response waveform which indicated residual displacement as large as BULLETIN OF THE NEW ZEALAND NATIONAL SOCIETY FOR EARTHQUAKE ENGINEERING, VOL. 16, NO. 4, DECEMBER 1983 one-half the maximum displacement amplitude. It is appreciated if the damage calculated by the analysis is described with respect to the cause of this large residual displacement. If the two earthquake motions gave similar characteristics, there must be something inherent to the structure rather than accidental drift.

Authors' reply:

Time-history analyses were performed for the first 10 seconds only of the accelerograms. This length of analysis was chosen because previous work had indicated that maximum member actions and structural deformation occur for both the El Centro and Pacoima Dam motions in this time. Some (plastic) deformations do occur after the 10 second mark and these may or may not help to restore the structure to its initial position. It is an observed fact that many buildings are left with residual displacements after a large seismic event. Thus the authors feel that the results obtained are credible, and that the structures investigated possess no inherent susceptibility to the development of large locked in deformations. Similar permanent inelastic deformations were predicted by numerous previous analyses also for framed buildings without structural walls.

Letter to the Editor

from Charles clifton*

Dear Sir,

re: Volume 15, No. 3 Structural Steel Test Photographs (1)

The comments contained in this letter correct false impressions which, in my opinion, are obtained when one studies the structural steel test photographs and accompanying comments in the bulletin, Volume 15, No. 3. The factual content in this letter is obtained from the paper in bulletin Volume 15, No. 2.(2)

The reading of these comments in conjunction with the photographs should give a correct interpretation of the behaviour of the members tested and the overall performance of these joints under cyclic loading.

The overall cyclic behaviour of a beam

Structural Engineer, N.Z. Heavy

Engineering Research Association, Manukau City, Auckland. 